\title{
The Cerebral Network of Parkinson's Tremor: An Effective Connectivity fMRI Study
}

\author{
Michiel F. Dirkx, ${ }^{1,2}$ Hanneke den Ouden, ${ }^{1}$ Esther Aarts, ${ }^{1}$ Monique Timmer, ${ }^{1,2}$ Bastiaan R. Bloem, ${ }^{2}$ Ivan Toni, ${ }^{1}$ \\ and Rick C. Helmich ${ }^{1,2}$ \\ ${ }^{1}$ Donders Institute for Brain, Cognition and Behavior, Centre for Cognitive Neuroimaging, Radboud University Nijmegen, 6500 HB Nijmegen, The \\ Netherlands, and ${ }^{2}$ Radboud University Medical Centre, Donders Institute for Brain, Cognition and Behaviour, Department of Neurology and Parkinson \\ Centre Nijmegen (ParC), 6500 HB Nijmegen, The Netherlands
}

Parkinson's resting tremor has been linked to pathophysiological changes both in the basal ganglia and in a cerebello-thalamo-cortical motor loop, but the role of those circuits in initiating and maintaining tremor remains unclear. Here, we test whether and how the cerebello-thalamo-cortical loop is driven into a tremor-related state by virtue of its connectivity with the basal ganglia. An internal replication design on two independent cohorts of tremor-dominant Parkinson patients sampled brain activity and tremor with concurrent EMG-fMRI. Using dynamic causal modeling, we tested: (1) whether activity at the onset of tremor episodes drives tremulous network activity through the basal ganglia or the cerebello-thalamo-cortical loop and (2) whether the basal ganglia influence the cerebellothalamo-cortical loop through connectivity with the cerebellum or motor cortex. We compared five physiologically plausible circuits, model families in which transient activity at the onset of tremor episodes (assessed using EMG) drove network activity through the internal globus pallidus (GPi), external globus pallidus, motor cortex, thalamus, or cerebellum. In each family, we compared two models in which the basal ganglia and cerebello-thalamo-cortical loop were connected through the cerebellum or motor cortex. In both cohorts, cerebral activity associated with changes in tremor amplitude (using peripheral EMG measures as a proxy for tremor-related neuronal activity) drove network activity through the GPi, which effectively influenced the cerebello-thalamo-cortical loop through the motor cortex. We conclude that cerebral activity related to Parkinson's tremor first arises in the GPi and is then propagated to the cerebellothalamo-cortical circuit.

Key words: cerebellum; effective connectivity; frontostriatal circuits; functional magnetic resonance imaging; Parkinson's

Significance Statement

Parkinson's resting tremor has been linked to pathophysiological changes both in the basal ganglia and in a cerebello-thalamocortical motor loop, but the role of those circuits in initiating and maintaining tremor remains unclear. Using dynamic causal modeling of concurrently collected EMG-fMRI data in two cohorts of Parkinson's patients, we showed that cerebral activity associated with changes in tremor amplitude drives network activity through the basal ganglia. Furthermore, the basal ganglia effectively influenced the cerebello-thalamo-cortical circuit through the motor cortex (but not the cerebellum). Our findings suggest that Parkinson's tremor-related activity first arises in the basal ganglia and is then propagated to the cerebello-thalamocortical circuit.

\section{Introduction}

Parkinson's disease is characterized by degeneration of dopaminergic cells in the midbrain, which leads to dopamine depletion in the striatum (Kish et al., 1988). One of the cardinal symptoms of Par-

\footnotetext{
Received Sept. 30, 2015; revised April 6, 2016; accepted April 7, 2016.

Author contributions: M.F.D., H.d.O., B.R.B., I.T., and R.C.H. designed research; E.A. and M.T. performed research; M.F.D. analyzed data; M.F.D., H.d.O., B.R.B., I.T., and R.C.H. wrote the paper.

This work was supported by the Dutch Brain Foundation [Grant F2013(1)-15 to R.C.H.] and the Netherlands Organization for Scientific Research (Grant VENI 016.135.023 to E.A. and Grant VENI 451-11-004 to H.E.D.). We thank Joshua Kahan for providing the adjusted matlab code for two-state DCM and useful suggestions concerning our DCM analyses, Dr. Jean Daunizeau for constructive thoughts regarding the best DCM approach for our research question, and Dr. Rianne Esselink for help with recruiting patients for this study.
}

kinson's disease is a low-frequency $(4-6 \mathrm{~Hz})$ resting tremor that has been linked to dopamine depletion in the pallidum (Helmich et al., 2011). Unlike other symptoms of Parkinson's disease, resting tremor is associated with pathophysiological changes, not only in the basal ganglia, but also in motor areas of a cerebello-thalamo-cortical loop. Specifically, metabolic and electrophysiological imaging has shown tremor-related activity in the cerebellar thalamus [ventral interme-

Correspondence should be addressed to Michiel F. Dirkx, Radboud, University Medical Centre, Neurology Department (HP 935), P.0. Box 9101, 6500 HB Nijmegen, The Netherlands. E-mail: michiel.dirkx@radboudumc.nl. DOI:10.1523/JNEUROSCI.3634-15.2016

Copyright $\odot 2016$ the authors $\quad 0270-6474 / 16 / 365362-11 \$ 15.00 / 0$ 
diate nucleus (VIM)], primary motor cortex, cerebellum, and the putamen (Timmermann et al., 2003; Fukuda et al., 2004; Helmich et al., 2011; Mure et al., 2011). Furthermore, electrophysiological studies have identified cells firing at tremor frequency both in the basal ganglia [subthalamic nucleus (STN) and pallidum] (Levy et al., 2000; Raz et al., 2000) and in the VIM (Lenz et al., 1994; Magnin et al., 2000). There is also clinical evidence that both the basal ganglia and the cerebello-thalamo-cortical loop are causally involved in tremor: deep brain stimulation (DBS) of basal ganglia nuclei [STN and internal globus pallidus (GPi)] and the VIM can both reduce tremor (Benabid et al., 1991; Lozano et al., 1995; Krack et al., 1997; Kumar et al., 2000).

Although it is clear that both the basal ganglia and the cerebellothalamo-cortical loop are involved in Parkinson's tremor, the circuit-level architecture of causal interactions remains unclear. The importance of taking a circuit-level perspective for understanding Parkinson's tremor is highlighted by recent evidence showing that tremor emerges from interactions between multiple oscillators in the STN and in the VIM (Cagnan et al., 2014) and from pathological GPi activity gaining access to motor areas of a cerebello-thalamo-cortical loop (Helmich et al., 2011). More precisely, we have suggested previously a model to explain the dual role of the basal ganglia and the cerebello-thalamo-cortical loop in Parkinson's tremor, the "dimmer-switch hypothesis" (Helmich et al., 2012). This model accounts for the observation that pallidal activity is transiently increased at the onset of tremor episodes, whereas activity in the cerebello-thalamo-cortical loop, but not the pallidum, is correlated with tremor amplitude (Helmich et al., 2011). According to this model, the basal ganglia trigger the tremor (like a light switch), whereas the cerebello-thalamo-cortical loop determines tremor amplitude (like a light dimmer). However, the basal ganglia could influence the cerebello-thalamo-cortical loop through different nodes and other nodes in addition to the basal ganglia could contribute to trigger a tremor episode. For instance, in macaques, the basal ganglia project to the cerebello-thalamo-cortical loop via both a connection from GPi to the motor cortex, where both circuits converge (Hoover and Strick, 1999), and through a connection from the STN to the cerebellar cortex (Bostan et al., 2010).

Here, we investigated whether the basal ganglia or the cerebellothalamo-cortical motor loop drive changes in tremor and how the basal ganglia and cerebello-thalamo-cortical motor loop are causally connected. Dynamic causal modeling (DCM) of fMRI data acquired during resting tremor episodes in Parkinson patients was used to distinguish between the neuronal dynamics predicted by different models of connectivity between basal ganglia and the cerebellothalamo-cortical loop (Friston et al., 2003). Building on recent applications of DCM to resting-state fMRI data in Parkinson's disease (Kahan et al., 2014) and essential tremor (Buijink et al., 2015), here, we use a similar method by using EMG data to detect tremor-related interactions between the basal ganglia [ $\mathrm{GPi}$, external globus pallidus (GPe), and STN] and the cerebello-thalamo-cortical loop (cerebellar cortex, thalamic VIM nucleus, and primary motor cortex).

Specifically, we test competing models of tremor onset activity in various systems using peripheral EMG measures as a proxy for central tremor-related neuronal activity. In addition, we test which interactions between the basal ganglia and the cerebellothalamo-cortical loop best explain the pattern of tremor-related activity in those regions.

\section{Materials and Methods}

Subjects

We investigated two independent cohorts of tremor-dominant Parkinson's disease patients (Table 1). Cohort 1 (C1) consisted of 19 patients
Table 1. Clinical characteristics of subjects

\begin{tabular}{lccc}
\hline Group & Cohort 1 $(n=19)$ & Cohort 2 $(n=22)$ & $p$-value \\
\hline Disease duration (y) & $4.9(2.8)$ & $4.3(2.1)$ & 0.4 \\
H\&Y & $2(1.5-3)$ & $2(1-3)$ & 0.9 \\
FAB & $16.9(0.8)$ & $17.0(1.3)$ & 0.8 \\
UPDRS & & & \\
$\quad$ Total & $28.5(8.7)$ & $29.4(6.2)$ & 0.7 \\
$\quad$ Nontremor (B + R) & & & \\
$\quad$ Most affected & $10.4(1.8)$ & $10.7(3.5)$ & 0.7 \\
$\quad$ Least affected & $4.6(3.7)$ & $4.7(2.3)$ & 0.8 \\
$\quad$ Axial & $7.6(3.5)$ & $6.3(2.3)$ & 0.3 \\
Rest tremor & & & \\
$\quad$ TRS & & & \\
$\quad$ Most affected & $3.6(1.4)$ & $3.0(1.2)$ & 0.2 \\
$\quad$ Least affected & $0.5(1.0)$ & $0.8(1.3)$ & 0.4 \\
$\quad$ UPDRS & & & \\
$\quad$ Most affected & $3.5(1.2)$ & $3.0(1.2)$ & 0.6 \\
$\quad$ Least affected & $0.5(1.1)$ & $0.8(1.3)$ & 0.5 \\
\hline
\end{tabular}

Disease characteristics of tremor-dominant patients of Cohort 1 and 2 are shown [Hoehn \& Yahr (H\&Y): median, minimum, and maximum scores in parentheses; other parameters: mean, SD in parentheses] and compared between groups (Kruskal-Wallis for H\&Y scales and for the least affected parts, otherwise 2-tailed and 2-samples $t$ test). Disease severity of each patient was measured using the H\&Y stages (maximum $=5$ ) stages and the UPDRS part III (UPDRS; maximum score is 108). B + R, Limb bradykinesia and rigidity (sum of UPDRS items 22-26). Axial, Axial symptoms (sum of UPDRS items 18, 19, 22, and 27-31). The Frontal Assessment Battery (FAB) was used as a measure of cognitive function (Dubois et al., 2000; maximum $=18$ ). Duration was defined as the time since subjective symptom onset (in years). Patients' resting tremor severity was scored using Part A of the Fahn-TolosaMarin Tremor Rating Scale (TRS) (Stacy et al., 2007; maximum = 8 points for each side) and item 20 of the UPDRS. Affected side did not differ between the two Cohorts $(p>0.2)$.

${ }^{a}$ Eight patients who did not receive a TRS test (Cohort 2) were left out.

( 10 men; aged $57 \pm 7$ years, average \pm SD) that have been described in a previous study (Helmich et al., 2011). Cohort 2 (C2) comprised 22 patients ( 11 men; $56 \pm 8$ years). Three patients from $\mathrm{C} 1$ were scanned again in $\mathrm{C} 2 \sim 5$ years after their initial scan for $\mathrm{C} 1$. All patients were righthanded and gave their written informed consent. Patients were included when they had idiopathic Parkinson's disease diagnosed according to the UK Brain Bank criteria. Exclusion criteria were as follows: cognitive dysfunction (Mini-Mental State Examination score $<24$ ), neurological or psychiatric comorbidity, severe head tremor, severe dyskinesias, and general exclusion criteria for fMRI. A tremor-dominant phenotype was defined as a rest-tremor score of $\geq 2$ on the Unified Parkinson Disease Rating Scale (UPDRS) for at least one hand during physical examination and a history of rest tremor. Furthermore, only subjects who had a tremor during the fMRI session, indicated by a visual peak in the EMG's power spectrum at $\sim 4-6 \mathrm{~Hz}$ (see below for specifics), were included. All patients were measured while off of dopaminergic medication (i.e., at least $12 \mathrm{~h}$ after intake of the last dose of their regular medication) on the evening before testing. The UPDRS scores of C2 were also retrieved when patients were in the on-medication state (i.e., when they had taken their own dopaminergic medication: levodopa equivalent daily dosage $=$ $407 \pm 191 \mathrm{mg}$, mean $\pm \mathrm{SD}$ ).

\section{Image acquisition and preprocessing}

fMRI was performed in all subjects on a 3T MRI system (Siemens). Subjects were instructed to lie still with eyes closed and to avoid falling asleep, which we confirmed with a postscan debriefing. fMRI first-level analyses were done using SPM8 (Wellcome Trust Centre for Neuroimaging, London; http://www.fil.ion.ucl.ac.uk). All functional images were (1) realigned, (2) slice time corrected to the first slice, (3) coregistered to a structural MRI image, (4) normalized to MNI space using unified segmentation (Ashburner and Friston, 2005), and (5) spatially smoothed using an $8 \mathrm{~mm}$ Gaussian kernel.

C1. For C1, we used a single-shot gradient echoplanar imaging (EPI) sequence $(\mathrm{TE} / \mathrm{TR}=30 / 1450 \mathrm{~ms} ; 21$ axial slices; voxel size $=$ $3.5 \times 3.5 \times 5.0 \mathrm{~mm}$; interslice gap $=1.5 \mathrm{~mm} ; \mathrm{FOV}=224 \mathrm{~mm}$; scanning time $=\sim 6 \mathrm{~min} ; 265$ images). Anatomical data were acquired using a magnetization prepared-rapid gradient echo sequence $(\mathrm{TE} / \mathrm{TR}=2.92 / 2.300 \mathrm{~ms}$; voxel size $=1.0 \times 1.0 \times 1.0 \mathrm{~mm} ; 192$ sagittal slices; FOV $=256 \mathrm{~mm}$ ). The first six images of each resting state session were removed. 
C2. For C2, we used a multiecho EPI sequence $\left(\mathrm{TE}_{1}=9.4 \mathrm{~ms} / \mathrm{TE}_{2}=\right.$ $21.2 \mathrm{~ms} / \mathrm{TE}_{3}=33 \mathrm{~ms} / \mathrm{TE}_{4}=45 \mathrm{~ms} / \mathrm{TR}=1820 \mathrm{~ms} ; 35$ axial slices; voxel size $=3.5 \times 3.5 \times 3.0 \mathrm{~mm}$; interslice gap $=0.5 \mathrm{~mm} ; \mathrm{FOV}=224 \mathrm{~mm}$; scanning time $=\sim 8 \mathrm{~min} ; 300$ images). After the acquisition of functional images, a high-resolution T1-weighted anatomical image was obtained. Thirty volumes, acquired before the start of the actual experiment, were used to estimate weights for a BOLD contrast-to-noise ratio map for each echo. Weighted summation was then used to combine all four echoes into a single dataset (Poser et al., 2006).

\section{Tremor-related EMG activity}

Muscle activity of the most affected forearm (wrist flexors and extensors) was measured using MR-compatible EMG (Brain Products; sampling frequency $=5000 \mathrm{~Hz}$ ) during fMRI scanning in all 41 patients. The same analysis described in our previous study (Helmich et al., 2011) was used and is briefly summarized here. First, BrainVision Analyzer 2.0 (Brain Products) was used for preprocessing the EMG data. Specifically, we: (1) used MR artifact correction (Allen et al., 2000), (2) downsampled to 1000 $\mathrm{Hz}$, (3) filtered with a $20-200 \mathrm{~Hz}$ band-pass filter to remove movement artifacts, and (4) rectified the signal to enhance the information on EMG burst-frequency (tremor) of the signal, thereby also recovering the lowfrequency EMG content (Myers et al., 2003). Next, EMG data were analyzed using FieldTrip (Oostenveld et al., 2011). Specifically, we calculated the time-frequency representations (TFRs) between 1 and $20 \mathrm{~Hz}$ in steps of $0.1 \mathrm{~s}$ using a $2 \mathrm{~s}$ Hanning taper, which resulted in a $0.5 \mathrm{~Hz}$ resolution. By averaging over all time points, we obtained an average power spectrum across segments. For each patient, we picked the TFR of the corresponding tremor frequency (i.e., the peak in the power spectrum between 4 and $6 \mathrm{~Hz}$; mean $\mathrm{Cl}=4.4 \pm 0.2 \mathrm{~Hz}$, mean $\mathrm{C} 2=4.6 \pm 0.1 \mathrm{~Hz}$ ), resulting in patient-specific regressors describing fluctuations in tremor amplitude (EMG-AMP). To remove outliers, we calculated the logarithmic values of the EMG-AMP and $z$-normalized the data within subjects. To capture activity related to changes in tremor amplitude (EMGCHANGE), we calculated the first temporal derivative of the EMG-AMP regressor. In this way, we used peripheral EMG measures (EMGCHANGE regressor) as a proxy for central tremor-related neuronal activity, testing where tremulous activity first arises in the network and how it is propagated to the rest of the network

\section{Tremor-related brain activity}

Tremor-related brain activity for $\mathrm{C} 1$ was described previously (Helmich et al., 2011). Effective connectivity findings for C1 have not been described before. We used the same method to test for tremor-related brain activity in $\mathrm{C} 2$. After convolution of both regressors with a hemodynamic response function, we considered EMG-AMP and EMG-CHANGE as explanatory variables in a multiple regression analysis. In addition, our first-level model included separate regressors of no interest: two regressors describing the signal intensity averaged on each scan over the segmented gray matter (i.e., global signal, to correct for head motion; Power et al., 2014) and over a blank portion of the MR images (out-of-brain signal) and 36 regressors describing head motion. Regressors describing head motion were based on linear, quadratic, and cubic effects of the six movement parameters belonging to each volume, as well as the first and second derivative of each of those regressors (to control for spin-history effects; Lund et al., 2005). Parameter estimates for all regressors were obtained by maximum likelihood estimation. For each subject, we calculated the average beta value of each region of interest (ROI; see below) using MarsBar (http://marsbar.sourceforge.net/) and then tested for significant group effects using one-sample $t$ tests (random-effects analyses) on these beta values.

\section{DCM of resting-state $f M R I$ data}

DCM is a Bayesian method of inference to model the causal influence that one neuronal system exerts over another (Friston et al., 2003). In contrast to functional connectivity, which measures dependency among BOLD signals, DCM estimates effective connectivity (i.e., directed coupling among neuronal responses). Operationally, effective connectivity is defined as the influence that one region exerts over another. It does this by using an a priori defined hypothesis about a neuronal system to specify connectivity parameters to construct neuronal models of interacting brain regions. Connectivity parameters may include fixed connections between nodes and exogenous inputs that cause perturbations of included nodes directly. These parameters are estimated such that the predicted BOLD response provides an accurate but parsimonious explanation for observed responses, as scored by variational free energy or model evidence. The model evidence is therefore a compromise between model complexity and accuracy and is simply the probability of observing the data $y$ under a particular model $m$. This model evidence can then be used for Bayesian model selection (BMS) to determine the most likely among a set of competing hypotheses about the mechanisms that generated the observed data (Penny et al., 2004; Stephan et al., 2009).

The original DCM approach was deterministic; that is, it used experimentally designed perturbations (e.g., a task demand or perceptual stimuli) as inputs that drive a neuronal network (Friston et al., 2003). Here, we were interested in spontaneous tremor amplitude modulations that characterize Parkinson's resting tremor. In this situation, there are no exogenous driving inputs. Stochastic DCM can partly account for this by including stochastic fluctuations in the differential state equations and using Bayesian filtering to estimate the hidden neuronal states, coupling parameters, and the precision of observation noise (Li et al., 2011; Daunizeau et al., 2012; Kahan et al., 2014). Here, we also used the EMG collected during scanning to identify time points at which tremor amplitude spontaneously changed (the unconvolved first temporal derivative of the tremor amplitude regressor). We used this regressor as a driving input to our models and compared it with a model in which there was no driving input. In other words, we supplemented a stochastic DCM with deterministic inputs (Li et al., 2011). For all of our DCM analyses, we used DCM12 and SPM12b (Wellcome Trust Centre for Neuroimaging, London; http://www.fil.ion.ucl.ac.uk).

\section{ROIs}

We included six ROIs into our model, the contralateral GPe, GPi, STN (as a hidden node, see below), primary motor cortex (MC), thalamic VIM nucleus, and the ipsilateral cerebellum (CBLM), relative to the most affected hand (i.e., where EMG was measured). We elected to study a subgraph or subset of nodes in the tremor-related system that was sufficient to address our hypotheses. The choice of these six nodes was motivated as follows. First, there is clear evidence that these six regions play a major role in tremor (for review, see Helmich et al., 2013). Specifically, using combined EMG-fMRI, we have previously shown tremor onsetrelated activity in all six regions (except the STN, due to limited scanning resolution), suggesting that they play a role in tremor initiation (Helmich et al., 2011). Furthermore, activity in the MC, VIM, and CBLM is correlated with tremor amplitude (Helmich et al., 2011; see Fig. 3), suggesting that these regions play a role in tremor amplification. Second, the inclusion of these six regions allowed us to model two separate pathways of interest between the basal ganglia and the cerebello-thalamo-cortical loop. These pathways are based on tracer studies in primates showing that the GPi is connected to the motor cortex (via the ventrolateral anterior nucleus of the thalamus; Hoover and Strick, 1999; Redgrave et al., 2010) and that the STN is connected to the cerebellar cortex (via the pons; Bostan et al., 2010). Third, the inclusion of the GPi, GPe, and STN allowed us to model the three major pathways between the motor cortex and the basal ganglia (direct pathway, indirect pathway, and hyperdirect pathway).

We included the STN as a hidden node (David et al., 2011; Moran et al., 2011; Marreiros et al., 2013; Kahan et al., 2014). This means that we did not include a BOLD time series for the STN, but that we enabled an inference on its afferents and efferents based on the influence that it exerts on nodes from which precise recordings were available (i.e., the GPi, motor cortex, and cerebellum). The reason was that the human STN has an estimated volume of $\pm 240 \mathrm{~mm}^{3}$ (Hardman et al., 2002), which, at our scanning resolution, amounts to 3 voxels $(\mathrm{C} 1)$ or 6 voxels $(\mathrm{C} 2)$ in native space. This obviously leads to major partial volume effects and thus an unreliable BOLD time series. This reliability translates into a trivial data precision, which is how (mathematically) hidden nodes are modeled in DCM. Because the STN connects the basal ganglia with the cerebellum (see above) and because the connectivity of the STN with 
Table 2. Tremor-related activity in Cohort 2

\begin{tabular}{|c|c|c|c|c|c|}
\hline \multirow[b]{2}{*}{ ROI } & \multirow{2}{*}{$\begin{array}{l}\text { Hemisphere } \\
\text { (wrt tremor) }\end{array}$} & \multicolumn{2}{|c|}{ Tremor amplitude } & \multicolumn{2}{|c|}{$\begin{array}{l}\text { Changes in tremor } \\
\text { amplitude }\end{array}$} \\
\hline & & $T$ & $p$ & $T$ & $p$ \\
\hline MC & Contralateral & 4.27 & $<0.001^{*}$ & 1.14 & 0.13 \\
\hline VIM & Contralateral & 1.84 & $0.03^{*}$ & 0.03 & 0.49 \\
\hline CBLM & Ipsilateral & 3.3 & $<0.001^{*}$ & 0.19 & 0.43 \\
\hline GPi & Contralateral & 0.59 & 0.28 & 0.86 & 0.20 \\
\hline
\end{tabular}

Table shows statistical values of tremor-related cerebral activity in our predefined ROls of all patients in Cohort 2 . ROls were based on results of tremor-related cerebral activity in patients of Cohort 1 (Helmich et al., 2011) and included the cerebello-thalamo-cortical loop (CBLM-VIM-MC) as well as the GPi. Statistics were done using a 1 -sample $t$-test across the group. Consistent with the results of Cohort 1, there was significant tremor-amplituderelated activity in the ROIs of the cerebello-thalamo-cortical loop. However, in contrast to the results of Cohort 1, there was no significant activity related to changes in tremor in any of the four ROls.

*Significant effects.

other nodes may influence network dynamics, we included this region as a hidden node.

We also omitted several nodes that are part of the anatomical model space; for example, the striatum, dentate nucleus, and the ventrolateral anterior nucleus of the thalamus. The reason is threefold. First, previous research indicates that these regions play a minor role in resting tremor (Helmich et al., 2013) and we did not observe tremor-related activity in these nodes (Table 2). Second, we wanted to limit the complexity of our model, which rapidly increases with the addition of more nodes, leading to less reliable model-selection solutions. Third, inclusion of these nodes was not necessary for modeling the two hypothesized pathways between basal ganglia and cerebello-thalamo-cortical circuit. Therefore, the addition of these nodes to our DCM does not add to the explanatory power of our models. For the other five nodes, we used inclusion masks to create our ROI time series. The inclusion masks of the cerebello-thalamocortical loop were derived from clusters where we previously found tremor-amplitude related activity (Helmich et al., 2011). To enable direct comparisons between cohorts, we used the same ROIs in both cohorts. The GPi and GPe inclusion masks were anatomically defined masks part of the Basal Ganglia Human Area Template (BGHAT; Prodoehl et al., 2008). BOLD fMRI time series were then extracted from these regions using the first eigenvariate of all voxels in that region using the same general linear model as described in the "Tremor-related brain activity" section (Helmich et al., 2011).

\section{Model space}

We defined our model space based on our two research questions: (1) which node of the tremor circuit drives changes in tremor? and (2) how do the basal ganglia interact with the cerebello-thalamo-cortical loop? Our first question was where the tremor dynamics first arise within the cerebral network. This question could be answered at the level of the inputs: we specified five models where changes in tremor amplitude as measured by the EMG recordings entered as an input to one of the five ROIs (GPi, GPe, MC, VIM, and CBLM) and one model with no input to test whether activity related to changes in tremor amplitude positively contributes to model evidence (see also Buijink et al., 2015). Note that our inference here is not on the causal relationship between the input and brain activity, but rather answers where these tremor dynamics are first observed within this network. We did not include a model with an input to the STN because this node was hidden. This means that, in principle, this hidden node could be any brain region with the connectivity fingerprint specified by the model (i.e., any brain region inhibited by the GPe and that excites the GPi and cerebellum; Kahan et al., 2014). Therefore, detected effects may not be representative of the actual STN.

Our second question could be answered at the level of the model connections. For all models, we defined the following nine fixed connections based on anatomical evidence in nonhuman primates: (1) MC $\rightarrow$ CBLM (Brodal and Bjaalie, 1997), (2) CBLM $\rightarrow$ VIM (Evrard and Craig, 2008), (3) a backward and forward connection between MC and VIM (Kultas-Ilinsky et al., 2003), (4) MC $\rightarrow$ GPe (via striatum; indirect pathway), (5) $\mathrm{MC} \rightarrow \mathrm{GPi}$ (via striatum; direct pathway), (6) $\mathrm{MC} \rightarrow$ STN (hyperdirect pathway), (7) GPe $\rightarrow$ GPi (Albin et al., 1989; Alexander and Crutcher, 1990; Redgrave et al., 2010), (8) CBLM $\rightarrow \mathrm{GPe}$ (via striatum), and (9) CBLM $\rightarrow$ GPi (via striatum; Hoshi et al., 2005; Bostan and Strick, 2010; Bostan et al., 2010). We tested two different models with either a connection from GPi $\rightarrow$ MC (DeLong, 1990; Anderson and Turner, 1991) or STN $\rightarrow$ CBLM (Bostan et al., 2010) to distinguish whether the basal ganglia communicate with the cerebellothalamo-cortical circuit via the motor cortex or the cerebellum. Together with five input and one no-input models, this yielded $6 * 2=12$ models (Fig. 1).

Finally, we specifically modeled the sign (inhibitory or excitatory) of each connection using two-state DCM (Marreiros et al., 2008) following previous work by Kahan et al. (2014). Two-state DCM allows for specification of the sign of each connection by endowing each node with excitatory and inhibitory subpopulations in receipt of stochastic and deterministic input or endogenous activity. This is important because the striatum and pallidum send GABA-ergic projections (Albin et al., 1989), leading to a net inhibitory connection from $\mathrm{MC} \rightarrow \mathrm{GPi}$ (via striatum), $\mathrm{MC} \rightarrow \mathrm{GPe}$ (via striatum), $\mathrm{CBLM} \rightarrow \mathrm{STN}$ (via striatum), and $\mathrm{GPe} \rightarrow \mathrm{STN}$ and GPi $\rightarrow$ MC (via thalamus; Shinoda et al., 1985; Horne and Butler, 1995). All other (long-range) connections are glutamergic and thus excitatory.

\section{Model selection}

Models were inverted using generalized filtering, which is a Bayesian filtering scheme for nonlinear state-space models in continuous time (Friston et al., 2010; Li et al., 2011). This provides an estimate of the coupling parameters and model evidence. After this estimation, we performed a random-effects BMS over our two sets of families (i.e., input and connection families), thereby computing the expected and (protected) exceedance posterior over competing models (Rigoux et al., 2014). This was done separately for $\mathrm{C} 1$ and C2.

\section{Results}

All patients had a tremor-dominant phenotype of Parkinson's disease, indicated by a mean tremor amplitude score of the most affected upper extremity of 2.4 (part 20 of the UPDRS-III scale, maximum score $=4)$. Patients were at a relatively early stage of the disease (average disease duration $=4.6$ years, total UPDRS off medication $=29.0$ ). There were no significant differences in disease characteristics between C1 and C2 (Table 1).

\section{Tremor-related brain activity}

We used combined EMG-fMRI to determine two types of tremor-related brain activity: activity that correlated with tremor amplitude and activity that correlated with changes in tremor amplitude. Tremor-related cerebral activity (not effective connectivity) from $\mathrm{C} 1$ has been described previously (Helmich et al., 2011) and shows tremor-amplitude-related activity in CBLM, VIM, and MC (Fig. 2A). We replicated these findings in C2 (Fig. $2 B)$. An ROI analysis showed significant tremor-amplituderelated activity in the contralateral MC, ipsilateral CBLM, and contralateral VIM (Table 2). An illustrative example of one patient showing how the (convolved) EMG-derived tremor signal relates to the BOLD signal is shown in Figure 3. A whole-brain search confirmed these findings (MC: peak at MNI coordinates $[-26,-28,+48]$, cluster of 429 voxels, $p<0.001$ FWE corrected; CBLM: peak at $[+6,-76,-24], 619$ voxels, $p<0.001$ FWE corrected) and revealed no additional brain areas at this threshold. These results show that tremor amplitude is related to cerebral activity in the cerebello-thalamo-cortical loop. Unlike in $\mathrm{C} 1$, we did not find significant activation explained by changes in tremor amplitude in the basal ganglia or cerebello-thalamocortical loop in C2. It should be noted, however, that the mean beta values of this univariate result (average tremor-changerelated activity in the GPi) were not significantly different between cohorts $\left(t_{(29)}=1.6, p=0.11\right)$. 
A Anatomical Model

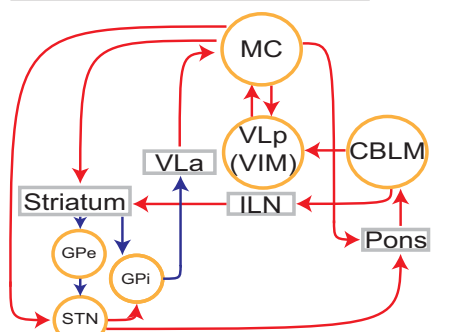

DCM implementation

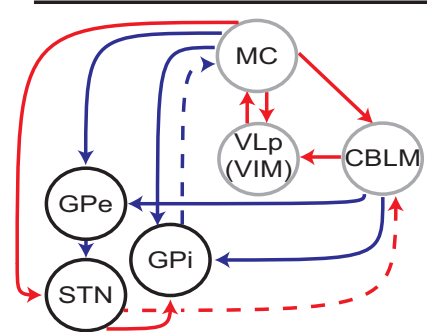

Two-state conversion

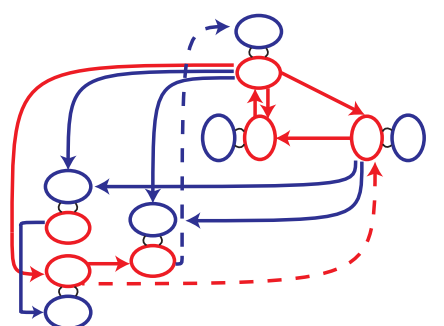

B

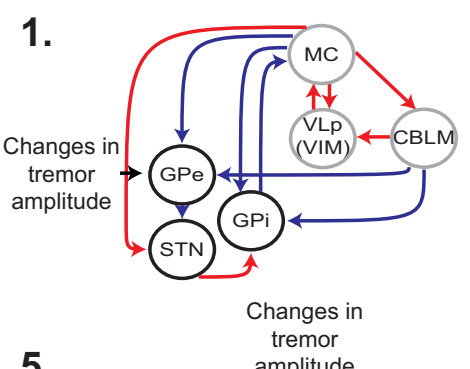

5.

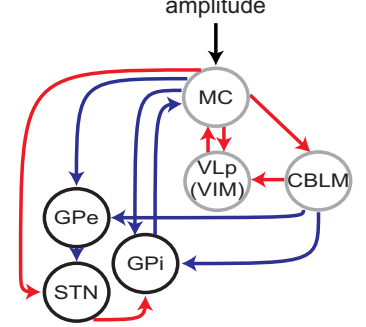

9.

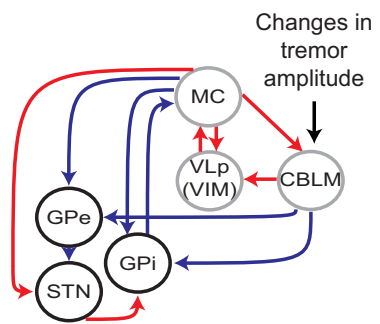

2.

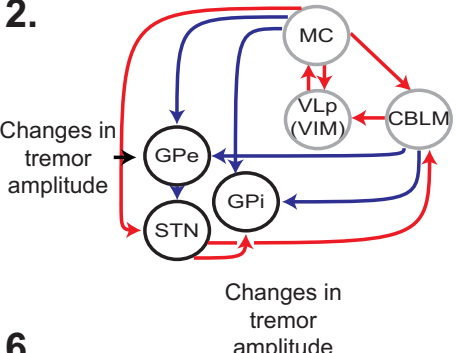

6.

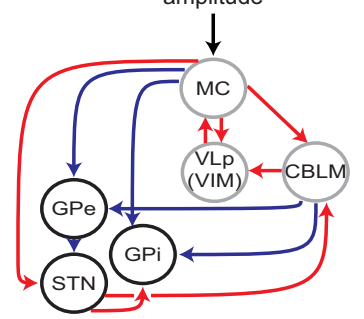

10.

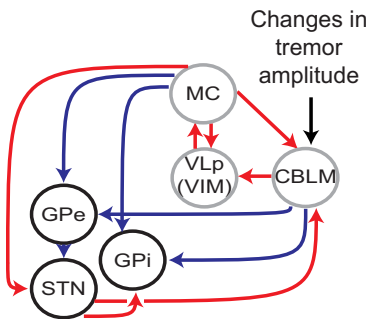

3.

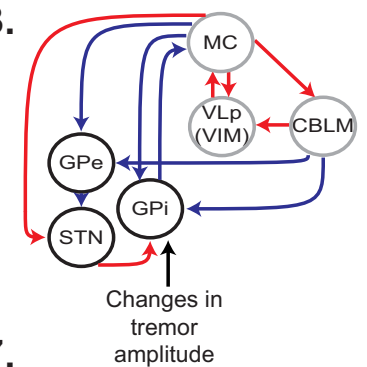

7.
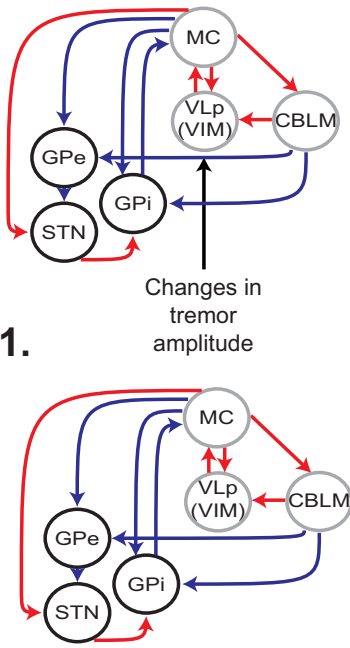

4.

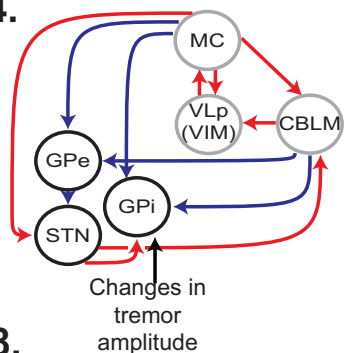

8. amplitude
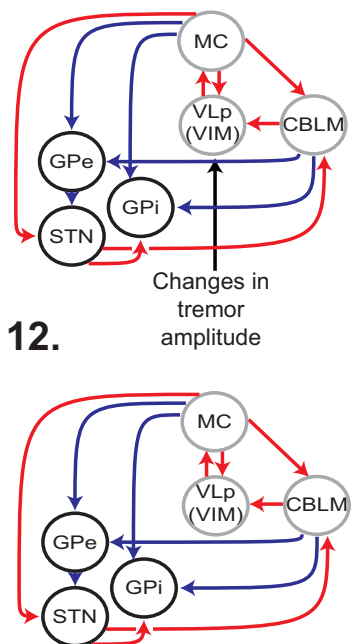

Figure 1. Schematic illustration of model space. A, Left, lllustration of the anatomical connections between the cerebello-thalamo-cortical loop and basal ganglia. Middle, Our DCM implementation of this anatomical model, which includes only the GPi, GPe, STN, MC, CBLM, and VIM. The dashed lines indicate variable connections representing our competing hypotheses. Right, Two-state implementation of these nodes, with blue indicating the inhibitory and red the excitatory part of each node. Inhibitory and excitatory connections are indicated by blue and red lines, respectively. $B$, All 12 competing models. Every model indicates a unique combination of an input to one of four measured nodes (GPe, GPe, MC, VIM, CBLM) and either a connection from GPi $\rightarrow$ MC or $\mathrm{STN} \rightarrow$ CBLM. In addition, the last two models have no input to test whether our tremor regressor positively contributes to the model evidence. VLa, Anterior part of venterolateral nucleus of thalamus; VLp, posterior part of venterolateral nucleus of thalamus; ILN, interlaminar nuclei.

\section{Model estimation and BMS}

All models were successfully inverted. A representative example of the predicted versus the observed BOLD response is plotted in Figure 4.

A BMS showed that, in both cohorts, model 3 was the clear winning model, indicated by an exceedance probability (XP) of $91 \%$ in $\mathrm{C} 1$ and $99 \%$ in $\mathrm{C} 2$. The protected exceedance probability (PXP) was even more convincing: $>99 \%$ in $\mathrm{C} 1$ and C2 (Fig. 5). When calculating the PXP first a null hypothesis (H0) is defined, which describes that the model frequencies in the population are equal (if there are $K$ models each is used in the population with a frequency of $1 / K)$. The alternative hypothesis (H1) describes that the model frequencies are not equal. Therefore, in contrast to the $\mathrm{XP}$, the PXP is more conservative because it is protected against the probability that the alternative hypothesis is not true (Rigoux et al., 2014). Put simply, this result means that model 3 is $>99 \%$ more likely than any of the other models, including a null model in which no EMG input was specified. Model 3 has two important features: (1) activity related to changes in tremor amplitude drives the network through the GPi (as opposed to other nodes) and (2) tremulous activity is propagated from the basal ganglia to the cerebello-thalamo-cortical circuit through an efferent connection from GPi toward the motor cortex (as opposed to a connection from the STN to the cerebellum). This finding suggests that tremor first arises in the GPi, which connects to the cerebello-thalamo-cortical circuit via the motor cortex. Further coupling parameters of this model can be found in Figure 5.

The average DCM input coupling parameter was centered around zero in both cohorts, with no significant difference between cohorts ( $p=0.28,2$-sample $t$ test). Importantly, this does 


\section{A Regions of Interest: cerebello-thalamo-cortical circuit}

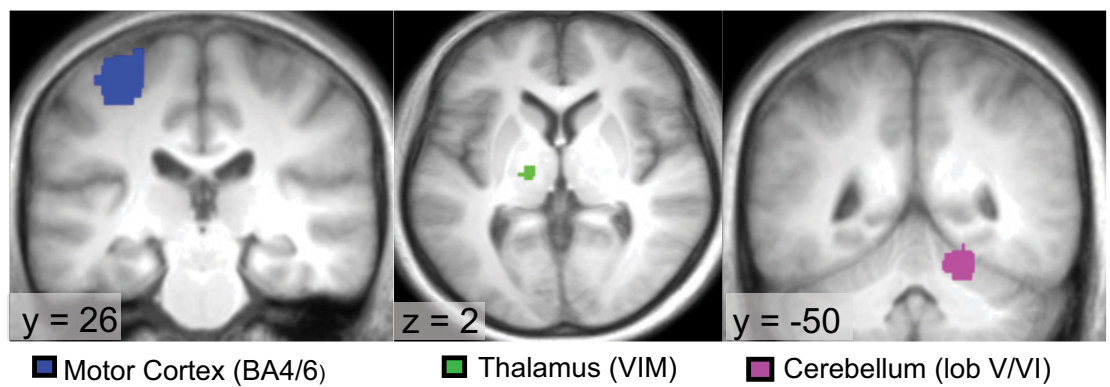

B Tremor amplitude related activity (Cohort 2) - cerebello-thalamo-cortical circuit

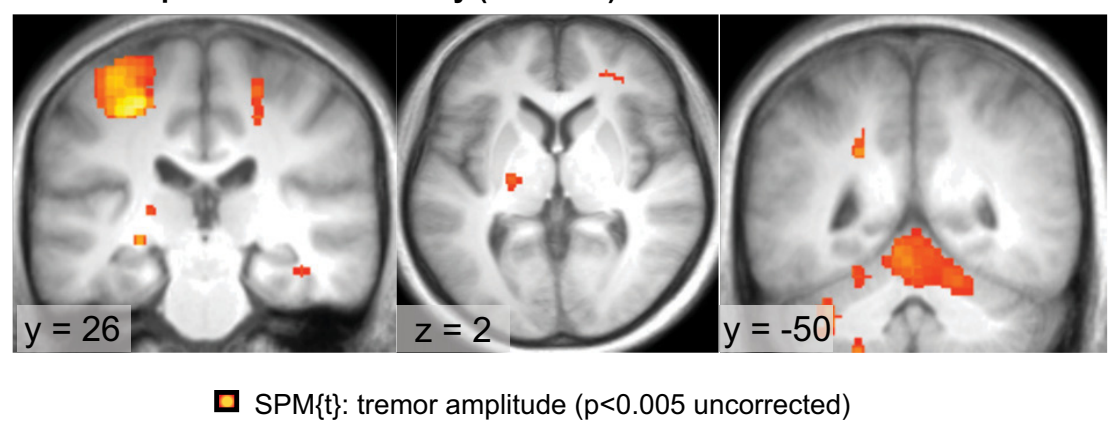

Figure 2. Tremor-related activity in the cerebello-thalamo-cortical loop. All images of patients with a left-sided affected arm were flipped so that the lateralization of the involved brain regions was the same among all subjects (i.e., corresponding to the most affected hand). $\boldsymbol{A}$, ROIs used for extraction of the time series of the contralateral motor cortex, contralateral thalamus (VIM), and ipsilateral cerebellum. These R0Is are based on second-level tremor-amplitude-related activity in C1 (Helmich et al., 2011). $\boldsymbol{B}$, Illustration of tremor-amplitude related activity of the cerebello-thalamo-cortical circuit in C2. Significant activation was found in all three ROI's, thus replicating the results of $\mathrm{C} 1$.

not mean that the input is irrelevant: our model comparison contained a model with no input ("null-model") and our DCM findings clearly show that our winning model (with input to the GPi) is more probable ( $>99 \%$ likely) than the null model. The apparent discrepancy between model-level and parameter-level results is a property of Bayesian inferential schemes; namely, the ability to dissociate between the goodness of a particular model architecture based on the data and the consistency of experimental effects on the model parameters across the population. For instance, interindividual differences in the estimated coupling parameter may emerge due to interindividual differences in hemodynamic parameters (Stephan et al., 2007). Following the guidelines of the field, we opted for an inference on model selection rather than on parameters (Stephan et al., 2010).

\section{Relationship with clinical symptoms}

There was no significant correlation between DCM parameters (input to the GPi, or coupling from $\mathrm{GPi}>\mathrm{MC}$ ) and clinical tremor severity (UPDRS score part 20). This is likely due to the limited between-patient variability in our clinical score (patients had a tremor severity of $2-4$ points on a scale of $0-4$ points) given our inclusion criterion (score $>2$ ).

\section{Relationship between univariate and DCM findings}

Our univariate EMG-fMRI analysis identified brain regions where activity is correlated with changes in tremor amplitude, but this analysis does not take into account network interactions. These interactions may propagate initial changes in one region to other nodes of the network, explaining why we observed tremor chang-related activity in several nodes of the tremor circuitry (Table 2). Conversely, DCM explicitly mod- els the underlying network interactions and allows for statistical comparisons between different models. This makes it possible to test where in the circuit tremulous activity first emerges. Our DCM findings therefore supplement the univariate findings by showing that, in both cohorts, activity in the GPi drives tremulous activity in the rest of the network. As expected, the two sets of results are related: there was a significant correlation between tremor-related activity in the GPi and the input parameters from the corresponding DCM model (where activity starts in the GPi: C1: $r=$ $0.45 ; p=0.026$; $22: r=0.37 ; p=0.047)$. The increased sensitivity of DCM may be driven by several factors: the fact that DCM takes network interactions into account at neuronal level and separation of neuronal and hemodynamic levels or because of the incorporation of other fluctuations in BOLD response captured by the stochastic aspect of the DCM (Daunizeau et al., 2012).

\section{Discussion}

We investigated the circuit-level cerebral mechanisms related to Parkinson's resting tremor. There are two main findings. First, at time points when tremor amplitude changes, cerebral activity first emerges in the GPi and is then propagated to the rest of the network. This finding adds an important piece of evidence to the hypothesis that the GPi triggers tremor episodes in Parkinson's disease (Helmich et al., 2011). Specifically, although tremor-related brain activity may reflect both afferent and efferent signals, DCM is able to identify which underlying neural circuit best explains that combination of signals given the network structure. By testing competing models of tremor onset activity in different network models (using peripheral EMG measures as a proxy for central tremor-related neuronal activity), we tested where in the network tremulous activity first arises. Therefore, whereas we found previously activity related to changes in tremor amplitude across several regions (GPe, GPi, cerebellum, VIM, and motor cortex; Helmich et al., 2011), here, we demonstrate that it is the GPi that drives cerebral activity in the rest of the network.

Second, the basal ganglia are effectively connected with the cerebello-thalamo-cortical loop via a connection from GPi to the motor cortex, but not via a connection from STN to the cerebellum. Therefore, although it is clear that there is an anatomical connection between the STN and the cerebellum (Bostan et al., 2010), its role in the generation of resting tremor seems limited.

\section{Role of the basal ganglia and the cerebello-thalamo-cortical loop in Parkinson's tremor}

Our results suggest that tremulous activity first arises in the GPi and is then propagated to the cerebello-thalamo-cortical loop. These findings are concordant with the "dimmer switch" hypothesis (Helmich et al., 2012). According to this hypothesis, the GPi switches the cerebello-thalamo-cortical loop on and off, which in turn behaves like a dimmer, modulating tremor intensity. 

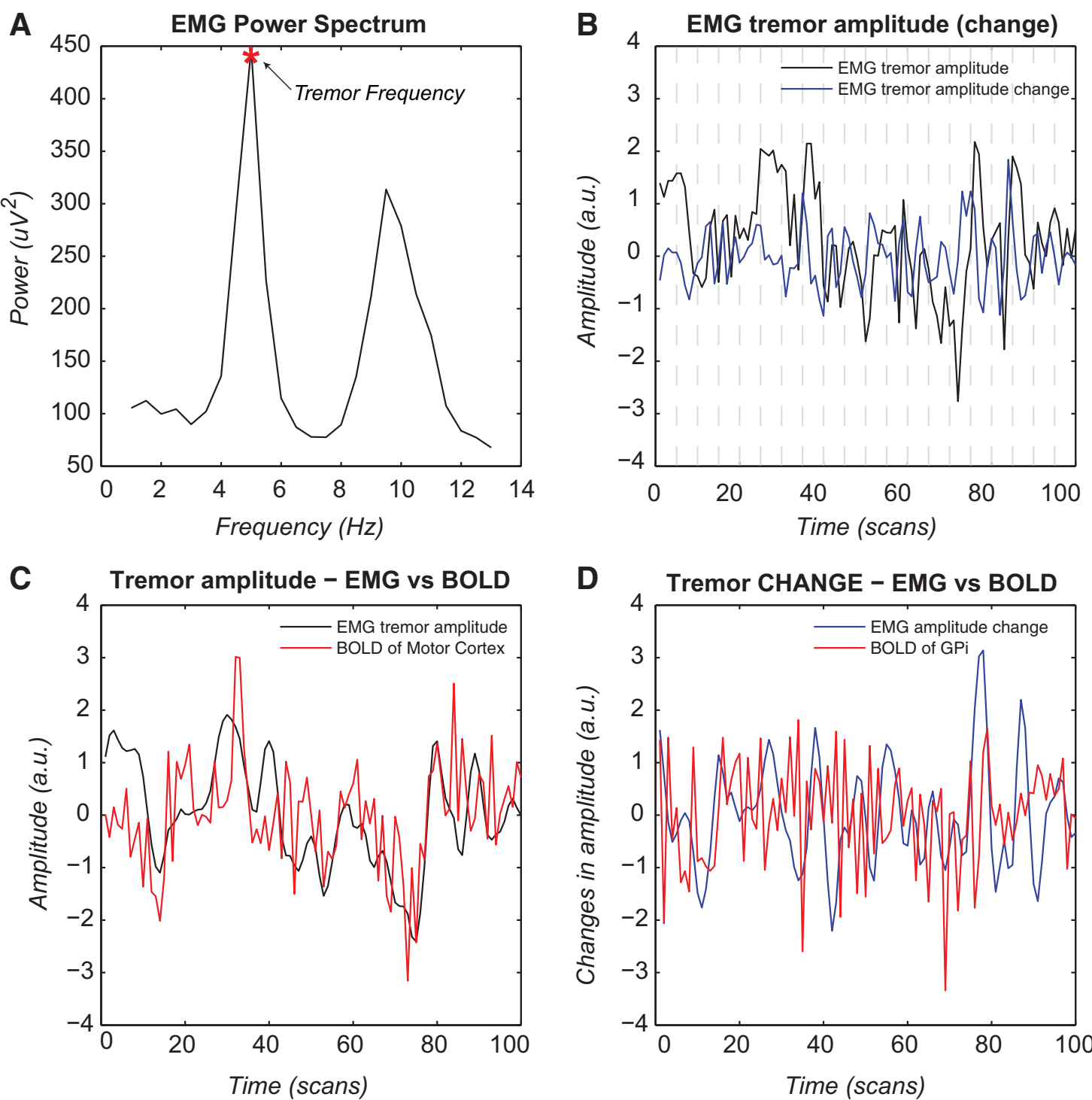

Figure 3. Tremor dynamics. This figure shows spontaneous tremor dynamics during scanning for one patient and the relationship between tremor variability and cerebral activity in the motor cortex and GPi. A, EMG power spectrum during scanning with the individual tremor frequency marked for this subject. $\boldsymbol{B}$, Spontaneous fluctuations in tremor amplitude (at the individual tremor frequency) during the scanning period (in black) plotted together with changes in tremor amplitude (in blue). C, Correlation between the convolved tremor amplitude regressor (in black) and the BOLD response of the MC (in red). $\boldsymbol{D}$, Correlation between the convolved tremor amplitude-change regressor (in blue) and the BOLD response of the GPi (in red). All regressors are high-pass filtered (cutoff 128 s), $z$-normalized, and log-transformed. Effects across the whole group are shown in Figure 2 and Table 2.

Tremor-related activity in the GPi may emerge as a consequence of dopamine depletion in this nucleus (Helmich et al., 2011), possibly due to selective degeneration of dopaminergic neurons in the retrorubral area of tremor-dominant Parkinson's patients (Hirsch et al., 1992). Furthermore, parkinsonian primates with resting tremor develop markedly increased correlations between remotely situated pallidal neurons (loss of segregation; Bergman et al., 1998) compared with healthy primates (Bar-Gad et al., 2003). This may lead to excessive synchronization in the basal ganglia, which fits with the emergence of tremor oscillations in the STN-GPe circuit (Plenz and Kital, 1999).

There is conflicting evidence as to whether there is a single oscillator (or pacemaker) involved in producing Parkinson's tremor or if the tremor emerges from an extended network (Helmich et al., 2013). Previous accounts have localized the tremor pacemaker either in the basal ganglia (STN-GPe circuit; Plenz and Kital, 1999) or in the cerebellar loop (hyper- polarized thalamic cells firing at $6 \mathrm{~Hz}$; Llinás, 1988). Others have emphasized the role of extended cerebral networks, for example, showing that network properties (altered thalamocortical connectivity) distinguish pathological tremors from voluntary tremor (Muthuraman et al., 2012) and that multiple nodes (i.e., both VIM and STN) have pacemaker properties (Cagnan et al., 2014). The latter study also showed a broad frequency-amplitude tolerance for Parkinson's tremor; that is, unchanged tremor amplitude with spontaneous changes in tremor frequency, suggesting that a cerebral network produces tremor. Our findings support a network view on tremor, suggesting that tremor emerges from the combined actions of the basal ganglia and cerebello-thalamo-cortical loop.

\section{Relationship with interference studies}

Previous studies have investigated the causal role of the STN and the nodes of the cerebello-thalamo-cortical circuit in Parkinson's resting tremor by stimulating these regions at tremor frequency, 

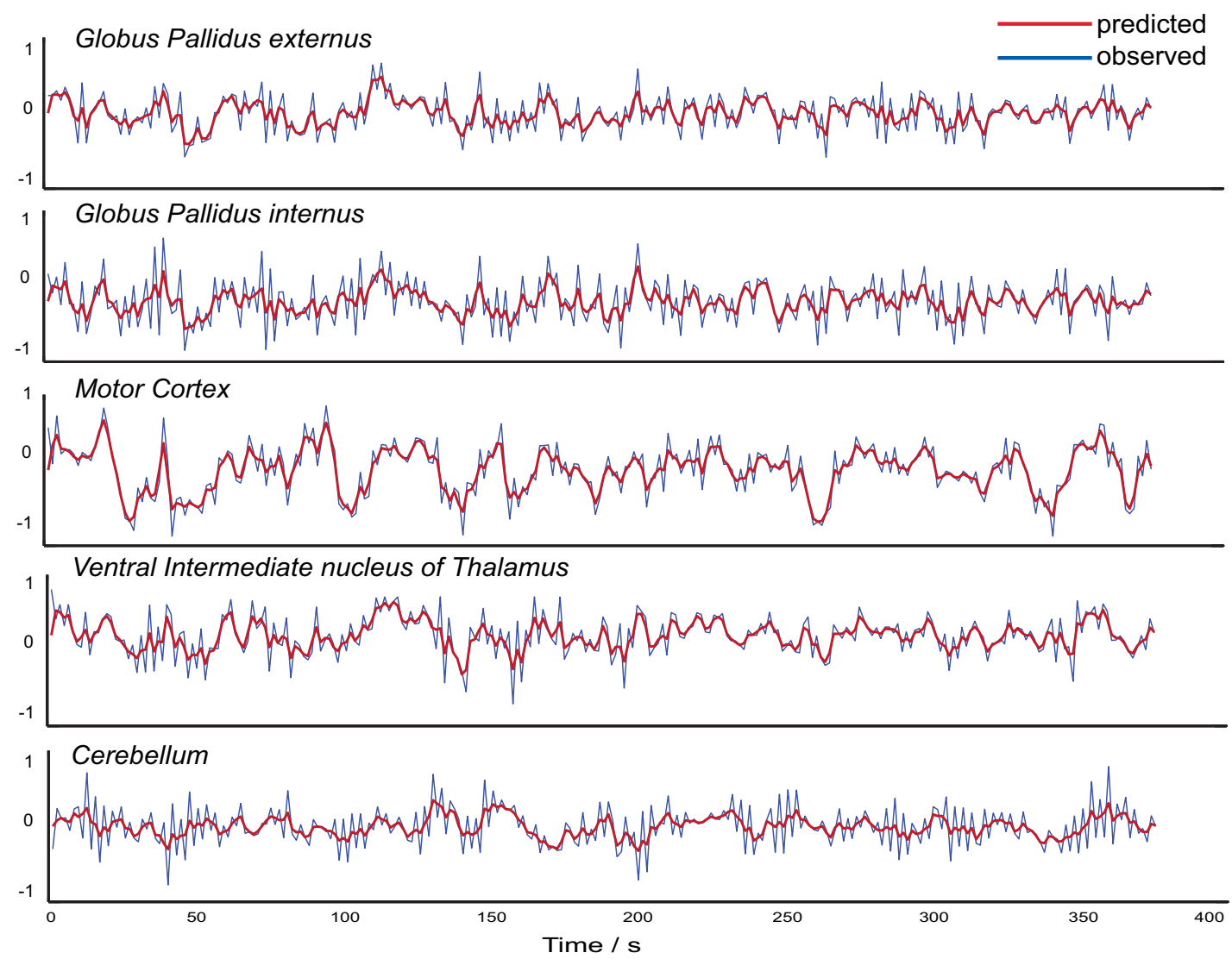

Figure 4. Observed versus predicted BOLD response. Representative example of observed versus predicted BOLD response (model 3; subject 2 of $\mathrm{C} 1$ ) in all of our measured ROIs.
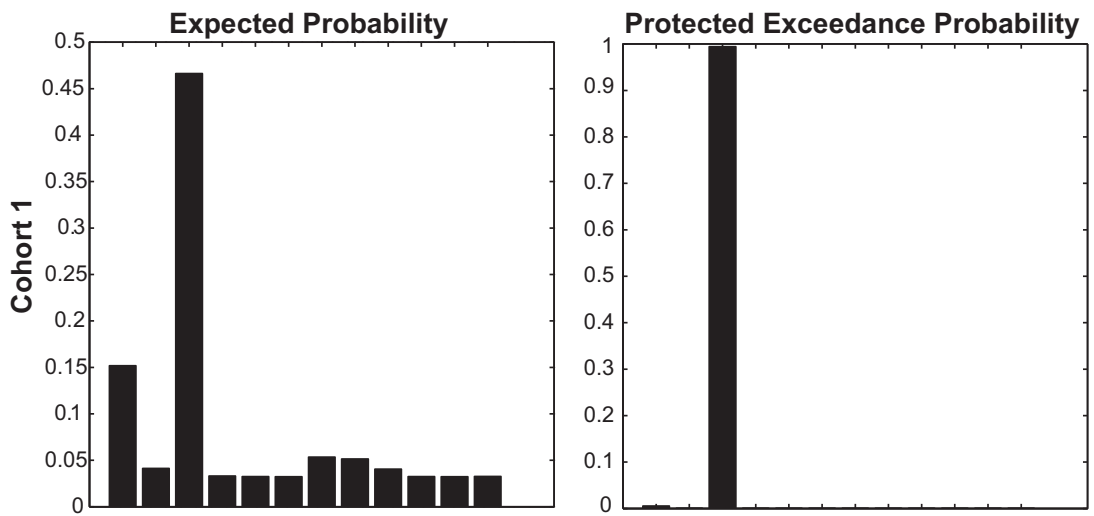

Winning model coupling parameters $(\mathrm{Hz})$
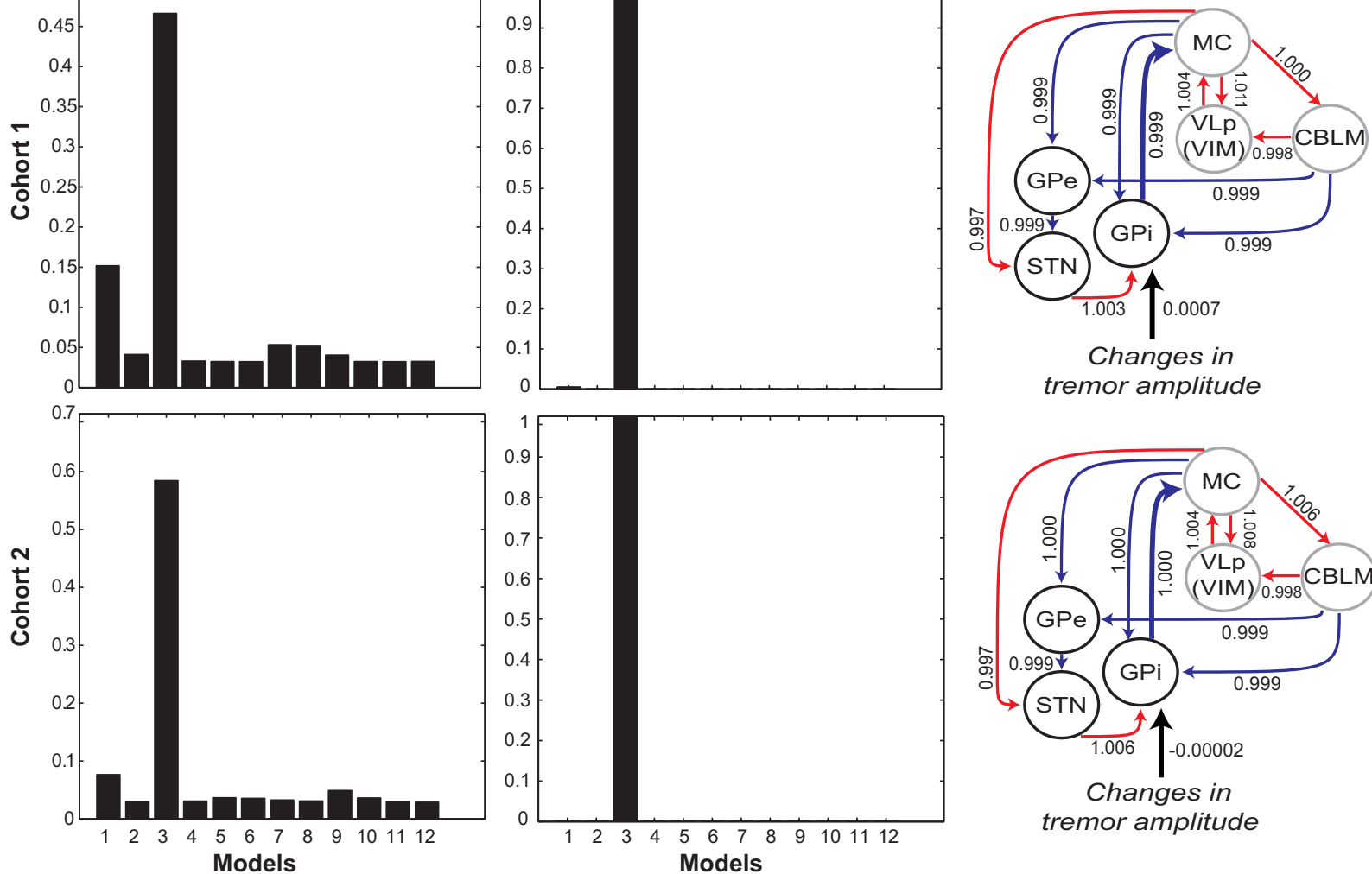

tremor amplitude

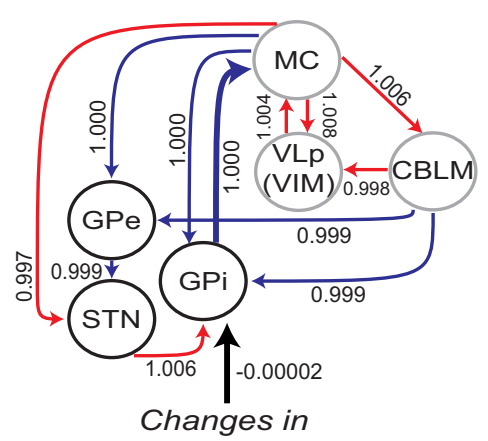

tremor amplitude

Figure 5. Results of BMS for $\mathrm{C} 1$ (top) and $\mathrm{C} 2$ (bottom). For both cohorts, model 3 (which specifies an input to the GPi and a connection from MC $\rightarrow$ GPi) is the clear winner, as indicated by a protected exceedance probability of $>99 \%$. 
and showing entrainment of the peripheral tremor (Brittain et al., 2013; Cagnan et al., 2014; Brittain et al., 2015). Others have used single-pulse magnetic stimulation to demonstrate tremor reset after stimulation of motor cortex, but not cerebellum (PascualLeone et al., 1994; Ni et al., 2010). Finally, intervening with activity in the STN, GPi, and VIM (using DBS) is known to decrease tremor severity (Benabid et al., 1991; Lozano et al., 1995; Krack et al., 1997; Kumar et al., 2000). However, it remains unclear whether the effects on tremor are related to the stimulated region or to remote effects onto other nodes of the network. By comparing different competing network structures, we tested explicitly how tremulous activity is propagated through the tremor network when tremor amplitude changes and how different nodes of the network (basal ganglia and cerebello-thalamo-cortical circuit) are effectively connected. Therefore, our finding that the tremulous activity first emerges in the GPi depends both on its local properties and on its specific position in the network. Two caveats of our approach are that the findings rely on the specific set of regions that we chose a priori to define the network and that fMRI does not allow us to test whether a region is necessary for tremor (as can be done using DBS). Future studies may combine DBS protocols with network analyses to reap the benefits from both approaches.

\section{Internal replication of results}

To quantify the variability and reliability of our results, we chose an internal replication design consisting of two cohorts. The main findings of this study are robust and confirmed across cohorts: both groups had tremor-amplitude-related activity in the cerebello-thalamo-cortical circuit and, in both cohorts, the same DCM model (where GPi drives tremulous activity in the rest of the network through GPi-motor cortex connectivity) won convincingly from all other models. However, although activity related to changes in tremor amplitude was present in $\mathrm{C} 1$, this failed to reach significance in C2. A possible explanation for this null finding in $\mathrm{C} 2$ is the well known variability in the dopamine response of resting tremor between Parkinson's patients (Helmich et al., 2012). This suggests that the magnitude of tremorrelated activity in the GPi may differ between patients, preventing significant effects at the group level.

\section{Interpretational issues}

It might be argued that the method we used (fMRI) lacks the temporal resolution required for investigating a $4-6 \mathrm{~Hz}$ tremor. However, unlike electrophysiological studies focusing on neural activity at (double) tremor frequencies (Timmermann et al., 2003), here, we considered neural activity and connectivity related to fluctuations in tremor amplitude. These fluctuations occur over multiple seconds (Gao, 2004), which is consistent with the temporal resolution of fMRI.

Tremor is likely the result of rapid, recurrent activity between (sub)cortical areas. For example, both in the basal ganglia and in the cerebello-thalamo-cortical loop, oscillatory neural activity is coherent with ongoing tremor at single and double tremor frequencies (Levy et al., 2000; Raz et al., 2000; Timmermann et al., 2003). The neuronal model of DCM cannot capture the temporal dynamics of these fast recurrent activity cycles, but rather reflects the activity envelope in shorter time bins (in the order of $100 \mathrm{~ms}$, dependent on the fMRI sampling rate). Reducing the duration of these time bins would not provide additional benefit given the temporal smoothness of the BOLD response. Therefore, the estimated model parameters reflect the net dynamics from the recurrent activity cycles within the cortico-subcortical network. The strong evidence in favor of tremor activity input entering the network in the GPi (rather than other nodes in the network) signifies that these net dynamics are best explained by tremorrelated activity first arising in the GPi.

One might argue that the lack of a healthy control group prevents inferences on the pathological nature of the findings. However, it is unclear how to effectively control for the occurrence of Parkinson's resting tremor in healthy subjects. Voluntary tremor is not an adequate control: although activity in the cerebellothalamo-cortical loop has been found for voluntary tremor in healthy subjects (Pollok et al., 2004; Muthuraman et al., 2012), this activity was never found in the GPi. Moreover, mimicked tremor obviously involves voluntary movements, whereas Parkinson's resting tremor is involuntary.

Finally, we included the STN as a hidden node in the network given our limited spatial resolution. This means that the neural state equation of the STN was determined by external perturbations and influences from other nodes in the network, but not by the region's own measured BOLD response (Kahan et al., 2014). When we estimated models that included the (noisy) BOLD response of the STN, we found that the same model was still the strongest in both cohorts (data not shown). Nonetheless, future high-resolution fMRI studies should focus on how the STN contributes to the tremor circuit.

\section{Conclusion}

Resting tremor in Parkinson's patients emerges from a distributed neural circuit in which tremulous activity first emerges in the GPi and is then propagated to the cerebello-thalamo-cortical circuit through the motor cortex. Our findings may have therapeutic implications, suggesting that resting tremor might be treated by preventing tremor signals (from the basal ganglia) to be amplified in the cerebello-thalamo-cortical circuit (Brittain et al., 2013).

\section{References}

Albin RL, Young AB, Penney JB (1989) The functional anatomy of basal ganglia disorders. Trends Neurosci 12:366-375. CrossRef Medline

Alexander GE, Crutcher MD (1990) Functional architecture of basal ganglia circuits: neural substrates of parallel processing. Trends Neurosci 13: 266-271. CrossRef Medline

Allen PJ, Josephs O, Turner R (2000) A method for removing imaging artifact from continuous EEG recorded during fMRI. Neuroimage 12: 230-239. CrossRef Medline

Anderson ME, Turner RS (1991) Activity of neurons in cerebellar-receiving and pallidal-receiving areas of the thalamus of the behaving monkey. J Neurophysiol 66:879-893. Medline

Ashburner J, Friston KJ (2005) Unified segmentation. Neuroimage 26: 839-851. CrossRef Medline

Bar-Gad I, Heimer G, Ritov Y, Bergman H (2003) Functional correlations between neighboring neurons in the primate globus pallidus are weak or nonexistent. J Neurosci 23:4012-4016. Medline

Benabid AL, Pollak P, Gervason C, Hoffmann D, Gao DM, Hommel M, Perret JE, de Rougemont J (1991) Long-term suppression of tremor by chronic stimulation of the ventral intermediate thalamic nucleus. Lancet 337:403-406. CrossRef Medline

Bergman H, Feingold A, Nini A, Raz A, Slovin H, Abeles M, Vaadia E (1998) Physiological aspects of information processing in the basal ganglia of normal and parkinsonian primates. Trends Neurosci 21:32-38. CrossRef Medline

Bostan AC, Strick PL (2010) The cerebellum and basal ganglia are interconnected. Neuropsychol Rev 20:261-270. CrossRef Medline

Bostan AC, Dum RP, Strick PL (2010) The basal ganglia communicate with the cerebellum. Proc Natl Acad Sci U S A 107:8452-8456. CrossRef Medline

Brittain JS, Probert-Smith P, Aziz TZ, Brown P (2013) Tremor suppression 
by rhythmic transcranial current stimulation. Curr Biol 23:436-440. CrossRef Medline

Brittain JS, Cagnan H, Mehta AR, Saifee TA, Edwards MJ, Brown P (2015) Distinguishing the central drive to tremor in Parkinson's disease and essential tremor. J Neurosci 35:795-806. CrossRef Medline

Brodal P, Bjaalie JG (1997) Salient anatomic features of the cortico-pontocerebellar pathway. Prog Brain Res 114:227-249. CrossRef Medline

Buijink AW, van der Stouwe AM, Broersma M, Sharifi S, Groot PF, Speelman JD, Maurits NM, van Rootselaar AF (2015) Motor network disruption in essential tremor: a functional and effective connectivity study. Brain 138:2934-2947. CrossRef Medline

Cagnan H, Little S, Foltynie T, Limousin P, Zrinzo L, Hariz M, Cheeran B, Fitzgerald J, Green AL, Aziz T, Brown P (2014) The nature of tremor circuits in parkinsonian and essential tremor. Brain 137:3223-3234. CrossRef Medline

Daunizeau J, Stephan KE, Friston KJ (2012) Stochastic dynamic causal modelling of fMRI data: should we care about neural noise? Neuroimage 62:464-481. CrossRef Medline

David O, Maess B, Eckstein K, Friederici AD (2011) Dynamic causal modeling of subcortical connectivity of language. J Neurosci 31:2712-2717. CrossRef Medline

DeLong MR (1990) Primate models of movement disorders of basal ganglia origin. Trends Neurosci 13:281-285. CrossRef Medline

Dubois B, Slachevsky A, Litvan I, Pillon B (2000) The FAB: a frontal assessment battery at bedside. Neurology 55:1621-1626. CrossRef Medline

Evrard HC, Craig AD (2008) Retrograde analysis of the cerebellar projections to the posteroventral part of the ventral lateral thalamic nucleus in the macaque monkey. J Comp Neurol 508:286-314. CrossRef Medline

Friston KJ, Harrison L, Penny W (2003) Dynamic causal modelling. Neuroimage 19:1273-1302. CrossRef Medline

Friston KJ, Stephan K, Li BJ, Daunizeau J (2010) Generalised filtering. Math Probl Eng 28:1-34.

Fukuda M, Barnes A, Simon ES, Holmes A, Dhawan V, Giladi N, Fodstad H, Ma Y, Eidelberg D (2004) Thalamic stimulation for parkinsonian tremor: correlation between regional cerebral blood flow and physiological tremor characteristics. Neuroimage 21:608-615. CrossRef Medline

Gao JB (2004) Analysis of amplitude and frequency variations of essential and Parkinsonian tremors. Med Biol Eng Comput 42:345-349. CrossRef Medline

Hardman CD, Henderson JM, Finkelstein DI, Horne MK, Paxinos G, Halliday GM (2002) Comparison of the basal ganglia in rats, marmosets, macaques, baboons, and humans: volume and neuronal number for the output, internal relay, and striatal modulating nuclei. J Comp Neurol 445:238-255. CrossRef Medline

Helmich RC, Janssen MJ, Oyen WJ, Bloem BR, Toni I (2011) Pallidal dysfunction drives a cerebellothalamic circuit into Parkinson tremor. Ann Neurol 69:269-281. CrossRef Medline

Helmich RC, Hallett M, Deuschl G, Toni I, Bloem BR (2012) Cerebral causes and consequences of parkinsonian resting tremor: a tale of two circuits? Brain 135:3206-3226. CrossRef Medline

Helmich RC, Toni I, Deuschl G, Bloem BR (2013) The pathophysiology of essential tremor and Parkinson's tremor. Curr Neurol Neurosci Rep 13: 378. CrossRef Medline

Hirsch EC, Mouatt A, Faucheux B, Bonnet AM, Javoy-Agid F, Graybiel AM, Agid Y (1992) Dopamine, tremor, and Parkinson's disease. Lancet 340: 125-126. Medline

Hoover JE, Strick PL (1999) The organization of cerebellar and basal ganglia outputs to primary motor cortex as revealed by retrograde transneuronal transport of herpes simplex virus type 1. J Neurosci 19:1446-1463. Medline

Horne MK, Butler EG (1995) The role of the cerebello-thalamo-cortical pathway in skilled movement. Prog Neurobiol 46:199-213. CrossRef Medline

Hoshi E, Tremblay L, Féger J, Carras PL, Strick PL (2005) The cerebellum communicates with the basal ganglia. Nat Neurosci 8:1491-1493. CrossRef Medline

Kahan J, Urner M, Moran R, Flandin G, Marreiros A, Mancini L, White M, Thornton J, Yousry T, Zrinzo L, Hariz M, Limousin P, Friston K, Foltynie T (2014) Resting state fMRI in Parkinson's disease: the impact of deep brain stimulation on 'effective' connectivity. Brain 137:1130-1144. CrossRef Medline

Kish SJ, Shannak K, Hornykiewicz O (1988) Uneven pattern of dopamine loss in the striatum of patients with idiopathic Parkinson's disease: pathophysiologic and clinical implications. N Engl J Med 318:876-880. CrossRef Medline

Krack P, Limousin P, Benabid AL, Pollak P (1997) Chronic stimulation of subthalamic nucleus improves levodopa-induced dyskinesias in Parkinson's disease. Lancet 350:1676. Medline

Kultas-Ilinsky K, Sivan-Loukianova E, Ilinsky IA (2003) Reevaluation of the primary motor cortex connections with the thalamus in primates. J Comp Neurol 457:133-158. CrossRef Medline

Kumar R, Lang AE, Rodriguez-Oroz MC, Lozano AM, Limousin P, Pollak P, Benabid AL, Guridi J, Ramos E, van der Linden C, Vandewalle A, Caemaert J, Lannoo E, van den Abbeele D, Vingerhoets G, Wolters M, Obeso JA (2000) Deep brain stimulation of the globus pallidus pars interna in advanced Parkinson's disease. Neurology 55:S34-S39. Medline

Lenz FA, Kwan HC, Martin R, Tasker R, Richardson RT, Dostrovsky JO (1994) Characteristics of somatotopic organization and spontaneous neuronal activity in the region of the thalamic principal sensory nucleus in patients with spinal cord transection. J Neurophysiol 72:1570-1587. Medline

Levy R, Hutchison WD, Lozano AM, Dostrovsky JO (2000) High-frequency synchronization of neuronal activity in the subthalamic nucleus of parkinsonian patients with limb tremor. J Neurosci 20:7766-7775. Medline

Li B, Daunizeau J, Stephan KE, Penny W, Hu D, Friston K (2011) Generalised filtering and stochastic DCM for fMRI. Neuroimage 58:442-457. CrossRef Medline

Llinás RR (1988) The intrinsic electrophysiological properties of mammalian neurons: insights into central nervous system function. Science 242 : 1654-1664. CrossRef Medline

Lozano AM, Lang AE, Galvez-Jimenez N, Miyasaki J, Duff J, Hutchinson WD, Dostrovsky JO (1995) Effect of GPi pallidotomy on motor function in Parkinson's disease. Lancet 346:1383-1387. CrossRef Medline

Lund TE, Nørgaard MD, Rostrup E, Rowe JB, Paulson OB (2005) Motion or activity: their role in intra- and inter-subject variation in fMRI. Neuroimage 26:960-964. CrossRef Medline

Magnin M, Morel A, Jeanmonod D (2000) Single-unit analysis of the pallidum, thalamus and subthalamic nucleus in parkinsonian patients. Neuroscience 96:549-564. CrossRef Medline

Marreiros AC, Kiebel SJ, Friston KJ (2008) Dynamic causal modelling for fMRI: a two-state model. Neuroimage 39:269-278. CrossRef Medline

Marreiros AC, Cagnan H, Moran RJ, Friston KJ, Brown P (2013) Basal ganglia-cortical interactions in Parkinsonian patients. Neuroimage 66: 301-310. CrossRef Medline

Moran RJ, Mallet N, Litvak V, Dolan RJ, Magill PJ, Friston KJ, Brown P (2011) Alterations in brain connectivity underlying beta oscillations in Parkinsonism. PLoS Comput Biol 7:e1002124. CrossRef Medline

Mure H, Hirano S, Tang CC, Isaias IU, Antonini A, Ma Y, Dhawan V, Eidelberg D (2011) Parkinson's disease tremor-related metabolic network: characterization, progression, and treatment effects. Neuroimage 54: 1244-1253. CrossRef Medline

Muthuraman M, Heute U, Arning K, Anwar AR, Elble R, Deuschl G, Raethjen J (2012) Oscillating central motor networks in pathological tremors and voluntary movements: what makes the difference? Neuroimage 60 : 1331-1339. CrossRef Medline

Myers LJ, Lowery M, O’Malley M, Vaughan CL, Heneghan C, St Clair Gibson A, Harley YX, Sreenivasan R (2003) Rectification and non-linear preprocessing of EMG signals for cortico-muscular analysis. J Neurosci Methods 124:157-165. CrossRef Medline

Ni Z, Pinto AD, Lang AE, Chen R (2010) Involvement of the cerebellothalamocortical pathway in Parkinson disease. Ann Neurol 68:816-824. CrossRef Medline

Oostenveld R, Fries P, Maris E, Schoffelen JM (2011) FieldTrip: Open source software for advanced analysis of MEG, EEG, and invasive electrophysiological data. Comput Intell Neurosci 2011:156869. CrossRef Medline

Pascual-Leone A, Valls-Solé J, Toro C, Wassermann EM, Hallett M (1994) Resetting of essential tremor and postural tremor in Parkinson's disease with transcranial magnetic stimulation. Muscle Nerve 17:800-807. CrossRef Medline

Penny WD, Stephan KE, Mechelli A, Friston KJ (2004) Comparing dynamic causal models. Neuroimage 22:1157-1172. CrossRef Medline

Plenz D, Kital ST (1999) A basal ganglia pacemaker formed by the subtha- 
lamic nucleus and external globus pallidus. Nature 400:677-682. CrossRef Medline

Pollok B, Gross J, Dirks M, Timmermann L, Schnitzler A (2004) The cerebral oscillatory network of voluntary tremor. J Physiol 554:871-878. CrossRef Medline

Poser BA, Versluis MJ, Hoogduin JM, Norris DG (2006) BOLD contrast sensitivity enhancement and artifact reduction with multiecho EPI: parallel-acquired inhomogeneity-desensitized fMRI. Magn Reson Med 55:1227-1235. CrossRef Medline

Power JD, Mitra A, Laumann TO, Snyder AZ, Schlaggar BL, Petersen SE (2014) Methods to detect, characterize, and remove motion artifact in resting state fMRI. Neuroimage 84:320-341. CrossRef Medline

Prodoehl J, Yu H, Little DM, Abraham I, Vaillancourt DE (2008) Region of interest template for the human basal ganglia: comparing EPI and standardized space approaches. Neuroimage 39:956-965. CrossRef Medline

Raz A, Vaadia E, Bergman H (2000) Firing patterns and correlations of spontaneous discharge of pallidal neurons in the normal and the tremulous 1-methyl-4-phenyl-1,2,3,6-tetrahydropyridine vervet model of parkinsonism. J Neurosci 20:8559-8571. Medline

Redgrave P, Rodriguez M, Smith Y, Rodriguez-Oroz MC, Lehericy S, Bergman H, Agid Y, DeLong MR, Obeso JA (2010) Goal-directed and habitual control in the basal ganglia: implications for Parkinson's disease. Nat Rev Neurosci 11:760-772. CrossRef Medline
Rigoux L, Stephan KE, Friston KJ, Daunizeau J (2014) Bayesian model selection for group studies revisited. Neuroimage 84:971-985. CrossRef Medline

Shinoda Y, Futami T, Kano M (1985) Synaptic organization of the cerebello-thalamo-cerebral pathway in the cat. II. Input-output organization of single thalamocortical neurons in the ventrolateral thalamus. Neurosci Res 2:157-180. CrossRef Medline

Stacy MA, Elble RJ, Ondo WG, Wu SC, Hulihan J; TRS study group (2007) Assessment of interrater and intrarater reliability of the Fahn-TolosaMarin Tremor Rating Scale in essential tremor. Mov Disord 22:833-838. CrossRef Medline

Stephan KE, Weiskopf N, Drysdale PM, Robinson PA, Friston KJ (2007) Comparing hemodynamic models with DCM. Neuroimage 38:387-401. CrossRef Medline

Stephan KE, Penny WD, Daunizeau J, Moran RJ, Friston KJ (2009) Bayesian model selection for group studies. Neuroimage 46:1004-1017. CrossRef Medline

Stephan KE, Penny WD, Moran RJ, den Ouden HE, Daunizeau J, Friston KJ (2010) Ten simple rules for dynamic causal modeling. Neuroimage 49: 3099-3109. CrossRef Medline

Timmermann L, Gross J, Dirks M, Volkmann J, Freund HJ, Schnitzler A (2003) The cerebral oscillatory network of parkinsonian resting tremor. Brain 126:199-212. CrossRef Medline 